SANDIA REPORT

$4 / 4 / 96$

SAND96-0776 • UC-700

Unlimited Release

Printed March 1996

\title{
Defense Programs Business Practices Re-engineering QFD Exercise
}

\author{
Carol Murray, Laura Halbleib
}

\section{Prepared by}

Sandia National Laboratories

Albuquerque, New Mexico 87185 and Livermore, California 94550

for the United States Department of Energy

under Contract DE-AC04-94AL85000

Approved for public release: on siribution is unlimited.

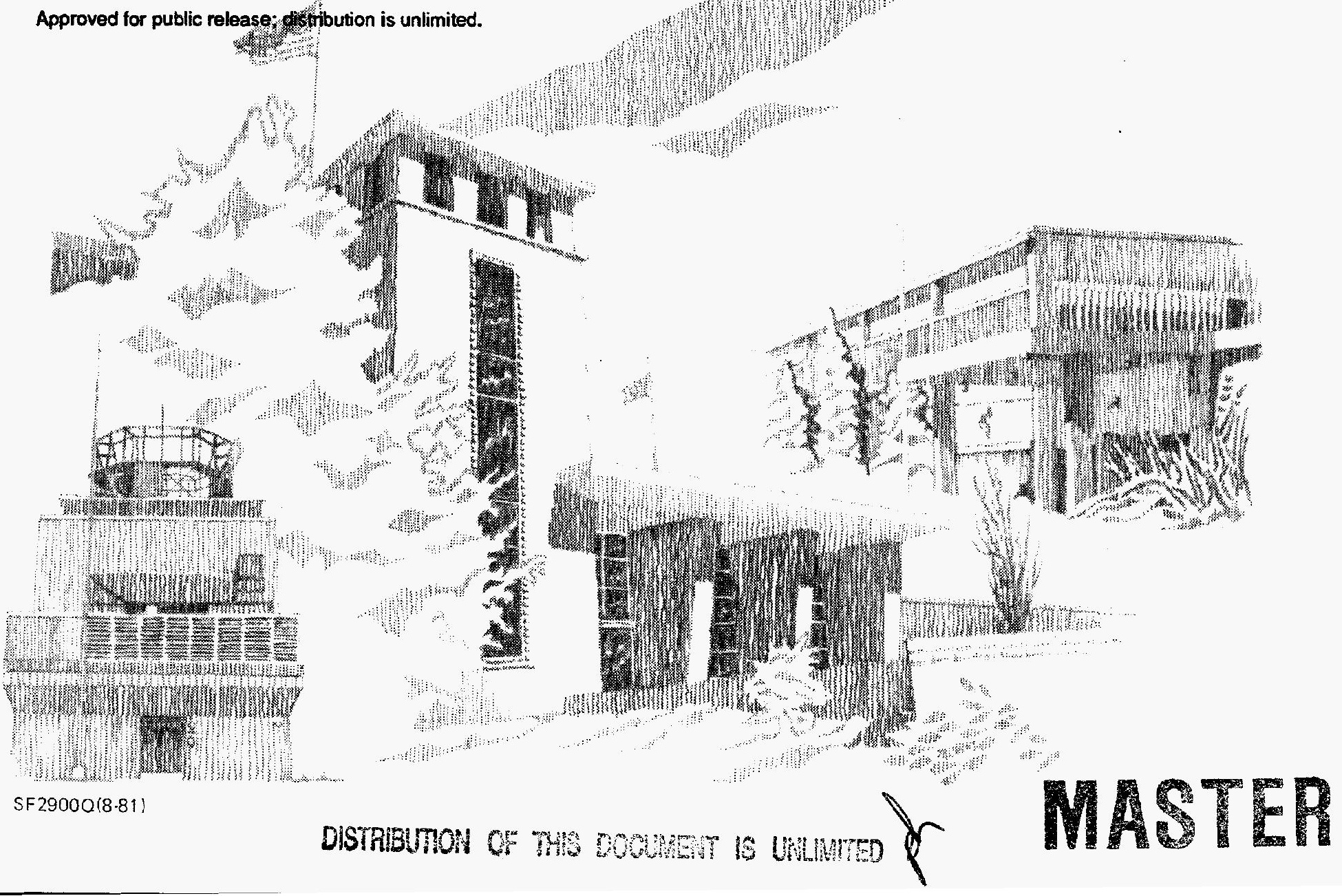


Issued by Sandia National Laboratories, operated for the United States Department of Energy by Sandia Corporation.

NOTICE: This report was prepared as an account of work sponsored by an agency of the United States Government. Neither the United States Government nor any agency thereof, nor any of their employees, nor any of their contractors, subcontractors, or their employees, makes any warranty, express or implied, or assumes any legal liability or responsibility for the accuracy, completeness, or usefulness of any information, apparatus, product, or process disclosed, or represents that its use would not infringe privately owned rights. Reference herein to any specific commercial product, process, or service by trade name, trademark, manufacturer, or otherwise, does not necessarily constitute or imply its endorsement, recommendation, or favoring by the United States Government, any agency thereof or any of their contractors or subcontractors. The views and opinions expressed herein do not necessarily state or reflect those of the United States Government, any agency thereof or any of their contractors.

Printed in the United States of America. This report has been reproduced directly from the best available copy.

Available to DOE and DOE contractors from

Office of Scientific and Technical Information

PO Box 62

Oak Ridge, TN 37831

Prices available from (615) 576-8401, FTS 626-8401

Available to the public from

National Technical Information Service

US Department of Commerce

5285 Port Royal Rd

Springfield, VA 22161

NTIS price codes

Printed copy: A03

Microfiche copy: A01 


\section{DISCLAIMER}

Portions of this document may be illegible in electronic image products. Images are produced from the best available original document. 


\title{
Defense Programs Business Practices Re-engineering QFD Exercise
}

\author{
Carol Murray \\ Quality Systems Department \\ Laura Halbleib \\ Statistics and Human Factors Department \\ Sandia National Laboratories \\ Albuquerque, New Mexico, 87185
}

\begin{abstract}
The end of the cold war has resulted in many changes for the Nuclear Weapons Complex (NWC). We now work in a smaller complex, with reduced resources, a smaller stockpile, and no new phase 3 weapons development programs. This new environment demands that we re-evaluate the way we design and produce nuclear weapons. The Defense Program (DP) Business Practices Re-engineering activity was initiated to improve the design and production efficiency of the DP Sector. The activity had six goals:

1. to identify DP business practices that are exercised by the Product Realization Process (PRP);

2. to determine the impact (positive, negative, or none) of these practices on defined, prioritized customer criteria;

3 . to identify business practices that are candidates for elimination or reengineering;

4. to select two or three business practices for re-engineering;

5. to re-engineer the selected business practices; and

6. to exercise the re-engineered practices on three pilot development projects.

Business practices include technical and well as administrative procedures that are exercised by the PRP.

A QFD exercise was performed to address (1)- (4). The customer that identified, defined, and prioritized the criteria to rate the business practices was the Block Change Advisory Group. Five criteria were identified: cycle time, flexibility, cost, product performance/quality, and best practices. Forty-nine business practices were identified and rated per the criteria.

From this analysis, the group made preliminary recommendations as to which practices would be addressed in the re-engineering activity. Sixteen practices will be addressed in the re-engineering activity. These practices will then be piloted on three projects:

- the Electronic Component Assembly (ECA)/Radar Project,

- the B61 Mod 11, and

- Warhead Protection Program (WPP).
\end{abstract}




\section{Executive Summary}

The end of the cold war has resulted in many changes for the Nuclear Weapons Complex (NWC). We now work in a smaller complex, with reduced resources, a smaller stockpile, and no new phase 3 weapons development programs. This new environment demands that we re-evaluate the way we design and produce nuclear weapons. The Defense Program (DP) Business Practices Re-engineering activity was initiated to improve the design and production efficiency of the DP Sector. The activity had six goals:

1. to identify DP business practices that are exercised by the Product Realization Process (PRP);

2. to determine the impact (positive, negative, or none) of these practices on the performance and efficiency of the PRP;

3. to identify business practices that are candidates for elimination or re-engineering;

4. to select two or three business practices for re-engineering;

5. to re-engineer the selected business practices; and

6. to exercise the re-engineered practices on three pilot development projects.

Business practices include technical and well as administrative procedures that are exercised by the PRP.

The DP Business Practices Quality Function Deployment (QFD) activity was developed to address the first four goals. This SAND report describes that QFD activity.

The QFD process consisted of the following steps:

1. Identify, prioritize, and define criteria for judging the impact of Business Practices on the PRP;

2. Identify, group, and define DP business practices;

3. Determine the impact of the business practices on the PRP using the criteria in (1); and

4. Based on impact, make recommendations on what business practices needed to be reengineered or eliminated.

Step 1 was performed by the customer of the Re-engineering effort, the Block Change Advisory Group. We scheduled a four-hour meeting in which the Advisory Group identified, defined and prioritized the criteria to evaluate the DP business practices. Five criteria were identified. In addition, each business practice was to be evaluated against each criteria for the practice as an isolated process and as a part of the overall PRP. The Advisory Group separated individual practice performance from the performance of the practice in the overall PRP system to determine if practices were being optimized individually, at the expense of the overall PRP.

The remaining steps were completed by a group of 25 managers and staff representing the business practices exercised by the PRP. These representatives included personnel from Allied Signal-Kansas City (KCD) and Sandia National Laboratories, California and New Mexico. This group participated in a one week meeting in which they identified and defined 
DP business practices, and evaluated those business practices against the Advisory Group's criteria. The practices were evaluated against the criteria using the Pugh Analysis technique.

From this analysis, the group made preliminary recommendations as to which practices would be addressed in the re-engineering activity. Sixteen practices will be addressed in the reengineering activity. These practices will then be piloted on three projects:

- the Electronic Component Assembly (ECA)/Radar Project,

- the B61 Mod 11, and

- Warhead Protection Program (WPP). 


\section{Introduction}

The end of the cold war has resulted in many changes for the Nuclear Weapons Complex (NWC). We now work in a smaller complex, with reduced resources, a smaller stockpile, and no new phase 3 weapons development programs. This new environment demands that we re-evaluate the way we design and produce nuclear weapons. The Defense Program (DP) Business Practices Re-engineering activity was initiated to improve the design and production efficiency of the DP Sector. The activity had six goals:

1. to identify DP business practices that are exercised by the Product Realization Process (PRP);

2. to determine the impact (positive, negative, or none) of these practices on the performance and efficiency of the PRP;

3. to identify business practices that are candidates for elimination or re-engineering;

4. to select two or three business practices for re-engineering;

5. to re-engineer the selected business practices; and

6. to exercise the re-engineered practices on three pilot development projects.

Business practices include technical and well as administrative procedures that are exercised by the PRP.

The DP Business Practices Quality Function Deployment (QFD) activity was developed to address the first four goals. This SAND report describes the QFD activity.

The QFD process consisted of the following steps:

1. Identify, prioritize, and define criteria for judging the impact of Business Practices on the PRP;

2. Identify, group, and define DP business practices;

3. Evaluate the impact of the business practices on the PRP using the criteria in (1); and

4. Based on impact, make recommendations on what business practices need to be reengineered or eliminated.

Step 1 was performed by the customer of the re-engineering effort, the Block Change Advisory Group. We scheduled a four-hour meeting in which the Advisory Group identified, defined and prioritized the criteria to evaluate the DP business practices. Five criteria were identified. In addition each business practice was to be evaluated against each criteria for the practice as an isolated process and as a part of the overall PRP. The Advisory Group separated individual practice performance from the performance of the practice in the overall PRP system to determine if practices were being optimized individually, at the expense of the overall PRP.

The remaining steps were completed by a group of 25 managers and staff representing the business practices exercised by the PRP. These representatives included personnel from Allied Signal-Kansas City (KCD) and Sandia National Laboratories, California and New Mexico. This group participated in a one week meeting in which they identified and defined 
DP business practices, and evaluated those business practices against the Advisory Group's criteria. The practices were evaluated against the criteria using the Pugh Analysis technique.

From this analysis, the group made preliminary recommendations as to which practices would be addressed in the re-engineering activity. Sixteen practices will be addressed in the reengineering activity. These practices will then be piloted on three projects:

- the Electronic Component Assembly (ECA)/Radar Project,

- the B61 Mod 11, and

- Warhead Protection Program (WPP).

\section{Step 1: Identifying, Defining, and Prioritizing Criteria}

The criteria for evaluating DP business practices were developed in a four-hour meeting with the Block Change Advisory Group. The meeting was video-conferenced between Sandia California and New Mexico. The Advisory Group defined the purpose of the meeting: to establish criteria against which to measure the effectiveness of DP processes and practices. The group then brainstormed possible evaluation criteria. Using the affinity process, they grouped similar criteria into similar categories. Because the meeting was video-conferenced, California and New Mexico sites separately grouped the brainstormed criteria. The two sites then reported their results and reconciled differences. Five criteria were identified:

1. Cycle Time,

2. Flexibility,

3. Cost,

4. Product Performance/Quality, and

5. Best Practices.

For each of the criteria, definitions were developed. Finally the criteria were prioritized. The criteria, their definitions, and their priorities are given in Attachment 1. In addition, the group determined that each business should be evaluated against the criteria:

1. as an isolated practice or process separate from the PRP, and

2. as a part of the overall PRP.

In a separate meeting Carol Murray (SNL), Laura Halbleib (SNL), and Dom Palamara (KCD) did a preliminary evaluation of three business practices to determine if the criteria would be useful in rating PRP systems and procedures. For this preliminary evaluation, the following processes were used:

- Supplier Contracting (does not include supplier qualification);

- Concurrent Qualification (not the EP401100 procedure but the implementation of concurrent qualification); and

- the Engineering Release System (e.g., AER, IER, EER, QER, etc.).

The results of the preliminary evaluation are given in Table 1. The evaluation uses the Pugh Matrix scoring method. The Pugh Matrix scoring method is used to assess the negative and positive aspects of items being studied against some defined criteria. Each item is scored on a scale of -2 to +2 for each criteria. For example, Supplier Contracting was given a score of -2 
against the cycle time criteria. This means, that for this example, Supplier Contracting has a strong negative impact on cycle time for the practice as an isolated activity and the practice's impact on the PRP as a system. In Pugh Matrix scoring:

- a -2 indicates a strong negative impact on the criteria;

- a -1 indicates that a practice has some negative impact;

- a 0 indicates that the process has no impact on that criteria;

- $a+1$ indicates some positive impact; and

- $a+2$ indicates a strong positive impact.

Each item is then scored by calculating its total positive and negative impact. The total negative impact is calculated by summing all negative Pugh scores. The total positive impact is calculated by summing all positive Pugh scores for each item. For example, the total negative impact of Concurrent Qualification as an individual practice is $-2(-1+-1)$; its total positive impact is $+4(+2++2)$. Weighted totals may also be calculated. These weighted totals incorporate the priority rating for each criteria. Weighted negative and positive totals are calculated by taking the inner product of the negative or positive scores with the associated priority rating for the criteria. For example, Concurrent Qualification as an individual practice has a total negative weighted score of $-8(-1 * 5+-1 * 3)$; its total positive weighted score is $+14(+2 * 2++2 * 5)$. Items with large negative scores are candidates for reengineering.

\begin{tabular}{|l|c|c|c|c|c|c|}
\hline \multicolumn{1}{|c|}{ Criteria (Priority) } & \multicolumn{2}{|c|}{ Supplier Contracting } & \multicolumn{2}{c|}{$\begin{array}{c}\text { Concurrent } \\
\text { Qualification }\end{array}$} & \multicolumn{2}{c|}{$\begin{array}{c}\text { Engineering Release } \\
\text { System }\end{array}$} \\
\cline { 2 - 7 } & Ind & Sys & Ind & Sys & Ind & Sys \\
\hline Product Quality (2) & -1 & -1 & +2 & +1 & -1 & +1 \\
\hline Cycle Time (5) & -2 & -2 & -1 & +2 & -1 & -1 \\
\hline Flexibility (5) & -2 & -2 & +2 & +1 & -2 & 0 \\
\hline Cost (3) & -2 & -1 & -1 & +2 & -2 & -1 \\
\hline Best Practices (2) & -2 & -2 & 0 & -1 & -2 & 0 \\
\hline Total Unweighted (+,-) & $0,-9$ & $0,-8$ & $+4,-2$ & $+6,-1$ & $0,-8$ & $+1,-2$ \\
\hline Total Weighted (+,-) & $0,-32$ & $0,-19$ & $+14,-8$ & $+23,-2$ & $0,-27$ & $+2,-8$ \\
\hline
\end{tabular}

Table 1. Preliminary Evaluation

In this preliminary evaluation, the criteria appeared to work well in rating DP business practices. A decision was made to continue with the QFD process.

\section{Step 2: Identify, Group, And Define DP Business Practices}

The DP Business Practices QFD meeting was held October 2-6, 1995. The goal of the meeting was to complete steps 2 and 3 of the QFD process and to provide input to step 4 . Attendees for the meeting are given in Attachment 2.

The attendees used the affinity process to brainstorm and group DP business practices. Several attempts at grouping brainstormed ideas were made. The number of attendees ( 28 
total) and the number of brainstormed business practices (approximately 200) contributed to the difficulty in grouping the practices. Consequently, the affinity process took two days to complete. The attendees finally grouped business practices in a matrix format by:

- PRP Subprocess; and

- Practice Type.

The list of PRP Subprocesses were:

- Marketing/Demand Generation;

- Design/Product \& Process Definition;

- Production Planning \& Scheduling;

- Get Materials;

- Fabrication \& Assembly;

- Certification and Delivery;

- Field Service; and

- Disposal.

The list of Practice Types were:

- Financial;

- Quality;

- Technical;

- Program Management;

- People;

- Strategic Planning;

- Information Systems; and

- Materials Management (including Procurement).

In addition, Legal and ES\&H Practice Types were identified. However, there were no representatives for either of these types at the meeting. Therefore, these practices were not addressed.

Forty-nine business practices were identified. These business practices are given in Attachment 3 by PRP Subprocess and Practice Type. The attendees were then divided into teams to develop definitions for the business practices. Teams were organized by business practice type. Attendees were assigned to teams based on their expert knowledge of the business practice type. The teams and their members were:

- Financial (Elena Holland, Helen Finley, Jake Gonzales, and Brian Behling);

- Quality (Jay Templin, Carol Murray, and Laura Halbleib);

- Technical (Mark Retter, Jim Van DeVreugde, Tom Davis, Mike Orrell, and Bob Yuhas);

- Program Management (Jon Barnette, Bill Packer, Chuck Oien, John Lankford, and Kent Parsons);

- People and Strategic Planning (Gary Ferguson, Keith Ortiz, and Nancy Clark);

- Information Systems (Alec Willis, Margaret Olson, Karen Long, Bob Rieden, and Gary Laughlin); and

- Materials Management (Jerry Record and Dom Palamara). 
Attachment 4 gives, for each business practice:

- its definition,

- the PRP subprocesses which utilize the practice,

- the business practice type, and

- what the practice includes and doesn't include (the scope of the business practice).

\section{Step 3: Evaluate The Impact Of The Business Practices On The PRP Using The Advisory Group Criteria}

The attendees then evaluated the business practices using the Advisory Group criteria. The Pugh Matrix scoring method described in Step 2 was used to score each practice. For each practice, weighted and unweighted totals for negative and positive values were calculated. High negative scores indicate that a practice might be a candidate for re-engineering.

Scoring for practices as independent processes was performed by the teams of knowledgeable experts. For example, scoring for all financial practices as independent processes was performed by the financial team. Scoring for impact on the overall PRP was done by individual attendees and then voted on as a group. The final overall PRP score for a particular practice and criteria was determined by a majority vote. Scores for practices as independent processes and overall impact on the PRP, and their totals are reported in Attachment 5.

\section{Step 4: Make Recommendations On What Business Practices Need To Be Re- Engineered Or Eliminated}

Once the scores were calculated for each practice, an analysis of the scores was performed. First, in reviewing the scores we noted that the individual and overall PRP scores did not differ greatly for each business practice. Second, the unweighted scores did not provide adequate differentiation between business practices to make decisions on what practices to reengineer. Thus, we decided to use the negative weighted totals for the business practices as part of the overall PRP system for the final analysis.

A histogram of the negative weighted totals on the overall impact of the PRP for all business practices is given in Attachment 6 . Five practices had a negative weighted score greater than or equal to 25 . These practices were:

- Staffing of Projects;

- Traceability of Design Requirements and Intent, Rationale and Decisions, and Processes;

- Engineering Development;

- Material Acceptance; and

- Procurement.

In general, the attendees agreed that these practices were prime candidates for re-engineering. However some concerns were noted. First, some attendees expressed the concern that in reengineering the identified business practices as separate from the overall PRP, these practices would be optimized individually, but could result in suboptimum performance of the overall 
PRP. Second, attendees were concerned that any re-engineering effort that was not focused on the "worker bee" would not be successful. Third, the attendees were concerned that any teams assigned to re-engineer the selected business practices, would not have the authority to implement the new practices. Fourth, some attendees were concerned that any teams assigned to re-engineer the selected business practices would not dedicate the time required to complete the re-engineering effort. Finally, a previous study with goals similar to this QFD effort was performed on the Mark 5 Arming Fusing and Firing (AF\&F). Some attendees were concerned that the results of this study would not incorporate the AF\&F study. These concerns are address in the following section and Final Recommendations.

\section{Reconciliation with Mk5 AF\&F Characterization Work}

This QFD presents a collective assessment of the appropriateness of various business practices for the future state described by the criteria. The participant population represents a broad spectrum of nuclear weapons components designers, systems engineers, and various support and administrative function. A comprehensive look of the W88 Mk $5 \mathrm{AF} \& \mathrm{~F}$ system and component development provides some comparable data from engineers associated with this discreet product realization which began with MCs/STS in December of 1983 and completed FPU in July 1998. This characterization study included a look at the schedule limiter/drivers to the W88, organizational relationships, things worth repeating, identifiable roadblocks to shorter cycle times, and the design teams' views on opportunities to shorten cycle time.

Some similarities and differences are noted when comparing the DP Business Practices QFD output and preliminary reports associated with the Mk 5 AF\&F. Further review of the data generated in the QFD will be provided by the Mk 5 AF\&F characterization team. It should also be noted that there were at least two participants common to each of these activities.

The following themes are common to the output of both activities:

1. A need to design with more margin.

2. A need for a network of suppliers approved for WR fabrication providing components which are well characterized at development.

3. A commercial components strategy is key.

4. Early involvement of the PA has not resulted in all the touted benefits of concurrent engineering. Specifically, production processing and producibility has not been impacted by early PA involvement. Including manufacturing engineering early may resolve this.

5. Subsystems are involved late; that is, after systems has committed to requirements.

6. The value of model-based design is questioned by the designers.

7. The designer viewpoint is that fewer development builds will result from

- more concurrence and inclusion in the requirements process, and

- solidification of requirements.

8. The QFD data shows procurement as a business practice in need of reengineering. The Mk5 characterization reports, specifically those from radar and 
stronglink indicate that when procurement was involved early the procurement process adequately supported product realization constraints. However, due to differences in procurement strategy between Sandia and KCD, the supplier selected in development often was not selected for procurement and this resulted in delays to the product realization cycle.

Items 2-8 will be addressed in the Final Recommendations.

\section{Data Analysis}

Tables 2 and 3 give summary statistics for the attendees scores for the weighted negative Pugh totals of the business practices impact on the overall PRP. Table 2 gives the average and standard deviation for the business practices with the top five most negatively weighted average scores on overall PRP impact. Table 3 gives the median and standard deviation for the business practices with the top five most negatively weighted median scores on overall PRP impact.

\begin{tabular}{|l|l|l|}
\hline \multicolumn{1}{|c|}{ Business Practice } & \multicolumn{1}{c|}{ Mean } & \multicolumn{1}{c|}{ Standard Deviation } \\
\hline Procurement & -23.680 & 6.030 \\
\hline Traceability of Design Requirements & -18.050 & 11.830 \\
\hline Engineering Development & -17.820 & 10.350 \\
\hline Supplier Selection/Development & -16.730 & 8.410 \\
\hline Staffing for a Project & -16.230 & 10.360 \\
\hline
\end{tabular}

Table 2.

\begin{tabular}{|l|l|l|}
\hline \multicolumn{1}{|c|}{ Business Practices } & \multicolumn{1}{c|}{ Median } & Standard Deviation \\
\hline Procurement & -25.0 & 6.030 \\
\hline Traceability of Design Requirements & -21.0 & 11.830 \\
\hline Engineering Development & -19.0 & 10.350 \\
\hline Staffing for a Project & -17.5 & 10.360 \\
\hline Manage Product Definition Information & -16.0 & 7.660 \\
\hline
\end{tabular}

Table 3.

Four business practices consistently received a higher negatively weighted score. The group scoring, the individual scoring median and mean scores listed the following four business practices with consistently high negative scores:

- Procurement,

- Traceability of Design Requirements,

- Engineering Development, and

- Staffing for a Project. 
However, scores for three of these business practices also had high standard deviations. High standard deviations indicate that there is disagreement among the attendees' individual scores.

\section{Final Recommendations}

Three projects were chosen to address, as a minimum, the top $20 \%$ negatively scored business practices. Sixteen out of the 49 business practices will be reviewed within these three projects. In addition, the Mk $5 \mathrm{AF} \& \mathrm{~F}$ results were also considered when identifying these projects. The projects are summarized below.

\section{Qualification Process Project}

The objective of this project is to develop and document a qualification process and plan for the Electronic Component Assembly (ECA)/Radar development activity. This project is sponsored by the ECA and radar pilots. Jay Templin, 12336, lead this project. The reengineering effort will address the following DP Business Practices:

- Supplier Development/Selection (-15),

- Supplier Certification/Qualification (-22),

- Product/Process Qualification (-8),

- Material Acceptance (-25),

- Supplier Management (-13),

- Receiving (-10),

- Procurement of WR Product (-27), and

- Assure Acceptable Material (-24).

\section{Engineering Design Process Project}

The objective of this project is to develop a detailed concurrent engineering development process flow for stockpile life extension programs. The B61 Mod 11 and the Warhead Protection Program (WPP) will pilot the outcome of this project, where appropriate. Mark Rosenthal, 5167, lead the project. Outcomes of this project are:

- a detailed structure to implement EP401099,

- early involvement and concurrent engineering techniques,

- links to requirements traceability and ER/CO,

- reductions in design build iterations, and

- a commercial component strategy. 
This project is sponsored by the Business Practices project. The following DP business practices will be addressed:

- Engineering Development (-25),

- Conceptual Design (-12),

- Create Design Definition (-12),

- Production Readiness (-15),

- Identify and Secure Resources (-20), and

- Staffing of Projects (-30).

\section{Engineering Information Systems Project}

The objective of this project is to support the development of a detailed engineering information system architecture. The scope will include the product realization process from design through disposal.

Project leadership has not been determined. A proposal by Keith Johnstone is being considered. This project will be coordinated with the Taos Beer Group (TBG) to remove duplication of effort and produce a product useful to TBG.

This project will be sponsored by the Business Practices project. The following DP business practices will be included:

- $\operatorname{ER/CO}(-20)$, and

- Traceability of Design Requirements (-26). 


\section{Attachment 1: Block Change Advisory Group Criteria}

\section{Reduce Cycle Time (5)}

\section{Phase 1:}

Concept through negotiated high-level DOE, DOD requirements with direction to proceed.

(Goal of 6 month cycle time for Sandia driven practices.)

Includes:

Anticipate Customer Requirements

Rapid Requirements Negotiation

\section{Phase 2:}

Agree to high-level DOE/DOD requirements with direction to proceed (e.g. PCP) to FPU. (Current goal of 2 years with continuous improvement.)

Includes:

Eliminate superfluous signature

Repeatable, predictable stable processes

Efficient execution of contractual agreements

Encourage concurrence of overall process

Assure Flexibility (5)

Enable flexibility to respond to changing requirements and unpredicted problems (e.g. loss of a supplier, stockpile vulnerability, national emergency, changing technology, political

environment, etc.)

Includes:

Flexibility to respond to unpredictable requirements

Rapidly formulate teams among complex and industrial partners

Rapid procurement and formation of partnerships

Ability to do cost performance tradeoffs early in PRP

\section{Reduce Cost (3)}

Reduce direct cost of practice. (Reducing by factor of 2 is the goal.) Leverage reduction of programmatic and project-related cost. (Degree of payoff. measure by impact to life Kyle cost.)

\section{Includes:}

Effective utilization of DOE human resources

Minimize Number of People

Reduce R\&D Cost

Reduce Production

Reduce NWC Cost

\section{Assure Product Performance/Quality (2)}

Assure product conforms to performance and program requirements.

Includes:

Optimize for stockpile stewardship

Improve predictability of PRP 


\section{Best Practice(2)}

Assure that the practice efficiently and effectively accomplishes what it is intended to do both as a practice and within a system.

Characteristics of a Good "System" of Practices

Includes:

Concurrence

Well defined

Easily Accessible

Consistent

Total Set Defined

Interoperability

Characteristics of "Individual" Practice

Includes:

Not Organizational Driven

Minimize interfaces

Flexibility to respond to unpredictability

Minimize Number of People

Minimize Process Steps

Minimize People who can say no

Predictable

No superfluous signatures

Implementable

Serve needs of People

Eliminate Duplication of effort

Value Added 
Attachment 2: Attendees List

\begin{tabular}{lll}
\multicolumn{1}{c}{ Name } & \multicolumn{1}{c}{$\underline{\text { Phone }}$} & \multicolumn{1}{c}{ Organization/Function } \\
Karen Marlman & $845-8201$ & $12323 /$ Facilitation Support \\
Dominick Palamara & $816-997-4784$ & ASKCD/ \\
M. Helen Finley & $845-8086$ & $2600 /$ \\
Jake F Gonzales & $845-8828$ & $2402 /$ \\
Carol Murray & $844-3611$ & 14004 \\
Elena Holland & $845-9597$ & $2402 /$ \\
Margaret Olson & $844-0870$ & $2122 /$ \\
Brian Behling & $845-9603$ & $2702 /$ \\
Gary Laughlin & $844-2787$ & $2503 /$ \\
Mark Retter & $844-2790$ & $5122 /$ \\
Nancy Clark & $845-8050$ & $2522 /$ \\
Jay Templin & $844-2129$ & $12336 / \mathrm{DP}$ Quality \\
Jim Van De Vreugde & $294-2702$ & $8417 /$ \\
Gary Ferguson & $845-9484$ & $14309 /$ \\
Kent Parsons & $844-2291$ & $2301 /$ \\
William E. Packer & $844-2344$ & $14304 /$ \\
Bob Yuhas & $845-9580$ & $2782 /$ \\
Chuck Oien & $294-2134$ & $5361 /$ \\
Mike Orrell & $845-9823$ & $5166 /$ \\
Jon Barnette & $844-8794$ & $2905 /$ \\
John Lankford & $816-997-4486$ & ASKCD/ \\
Alec Willis & $294-2641$ & $8203 /$ \\
Bob Rieden & $844-4894$ & $2604 /$ \\
Tom Davis & $816-997-5275$ & ASKCD/ \\
Gerry Record & $845-9444$ & $10250 /$ Procurement \\
Warren Sceiford & $845-8891$ & $2343 /$ \\
Karen Long & $844-7192$ & $2252 /$ \\
Keith Ortiz & $844-2072$ & $5102 /$ \\
& &
\end{tabular}

E-Mail

ksmarlm@sandia.gov

mhfinle@sandia.gov jfgonza@sandia.gov camurra@sandia.gov meholla@sandia.gov meolson@sandia.gov bjbehli@sandia.gov gllaugh@sandia.gov mjretter@sandia.gov nhclark@sandia.gov

jlvand@sandia.gov gmfergu@sandia.gov mkparso@sandia.gov wepacke@sandia.gov rjyuhas@sandia.gov ctoien@sandia.gov mgorrel@sandia.gov jhbarne@sandia.gov

arwilli@sandia.gov rfiede@sandia.gov tdavis@kcd.com glrecord@sandia.gov wrsceif@sandia.gov kslong@sandia.gov 
Attachment 3: Business Practices by PRP Subprocess and Practice Type

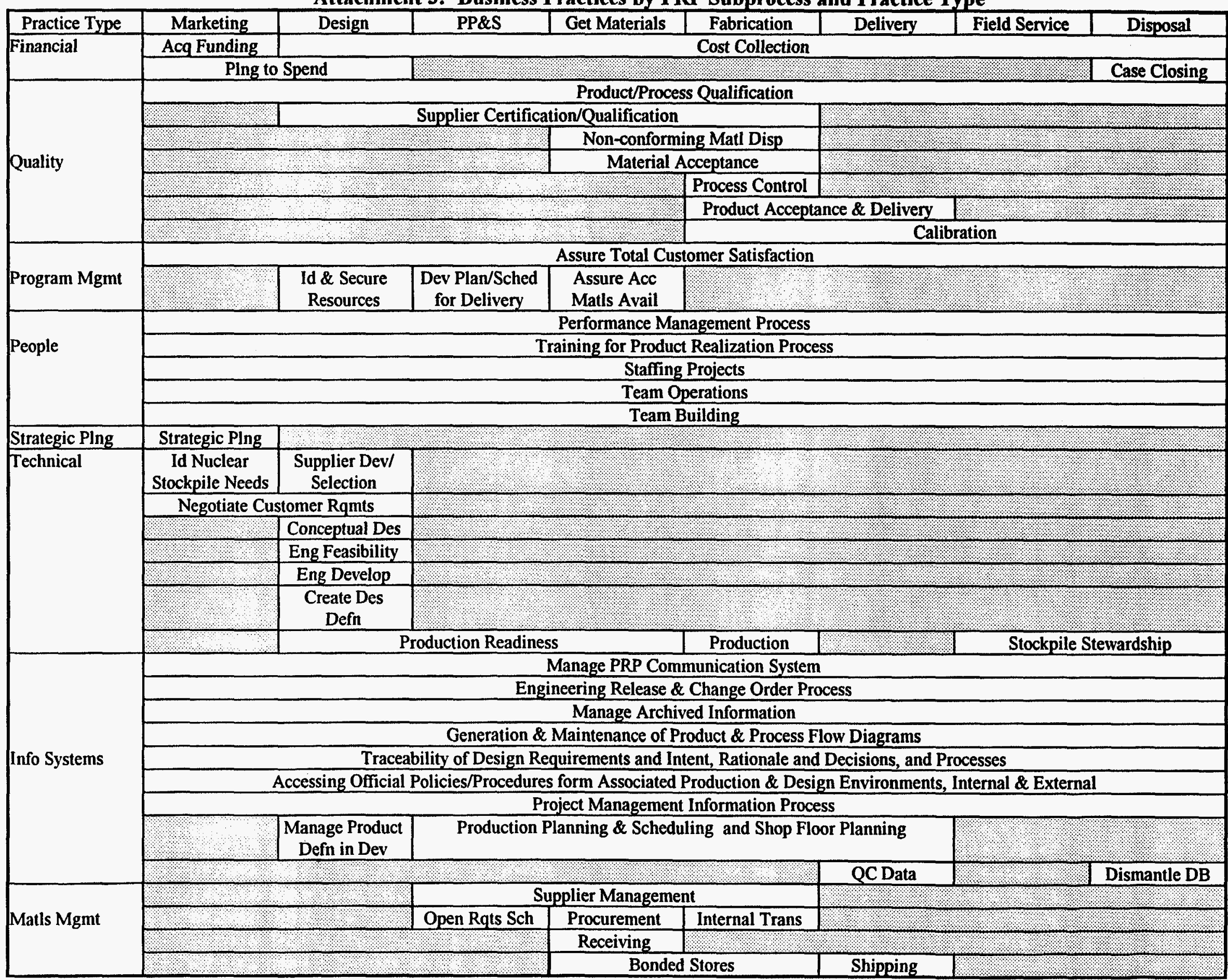




\section{Attachment 4: Business Practice Definitions}

Business Practice:

Acquiring Funding

Definition (25 words or less):

Process of acquiring DP funding. (Note: Demand generation is a continuous process; i.e., funds may come from an existing project/program.)

PRP Subprocesses:

Marketing/Demand Generation

Business Practice Type: Financial

Includes:

Proposal Process

Tech Transfer \& Commercialization

CRADA

ICOs into SNL

Doesn't Include:

Spending $\$$ acquired from sponsors

LDRD \$

\section{Business Practice:}

Planning to Spend

\section{Definition (25 words or less):}

The process of planning to spend $\$$ on your DP project. Begins with FIN Plan $\$$ in house(MIPR,B\&R

Line Item \#, etc.) Ends with approval of Program/Project from Program Manager.

\section{PRP Subprocesses:}

Marketing/Demand Generation, Design/Product \& Process Definition

Business Practice : Financial

\section{Includes:}

Case Authorization form (open case)

Case Status Update

Spend Plan Input (reflect. of Project Plan)

Capital Equipment Requirements

Subscriptions of Service Centers

Facility Mod. to accommodate. project work

\section{Doesn't Include:}

Project Planning

\section{Business Practice:}

Cost Collection

Definition (25 words or less):

The process of collecting, managing, theoretically controlling, reporting, \& tracking project costs.

PRP Subprocesses:

All except Marketing/Demand Generation

Business Practice Type : Financial

Includes:

Labor Charges

Direct Charges

Service Center Charges

Capital Equipment Charges

Controlling \& Monitoring of Costs

Reporting Costs: Std \& Ad Hoc

Doesn't Include: 


\begin{tabular}{|l|}
\hline Business Practice: \\
Case Closing \\
\hline Definition (25 words or less): \\
The process of closing out cases, stopping costs and stopping reporting of these costs. Begins with \\
completion of project. Ends with “the wake". \\
\hline $\begin{array}{l}\text { PRP Subprocesses: } \\
\text { Disposal (completion/delivery) }\end{array}$ \\
\hline Business Practice Type: Financial \\
\hline $\begin{array}{l}\text { Includes: } \\
\text { Reclasses of POs, SOs } \\
\text { ICTs of timecards, travel vouchers, other } \\
\text { Reconciliation of variances }\end{array}$ \\
\hline
\end{tabular}

\begin{tabular}{|c|c|}
\hline $\begin{array}{l}\text { Business Practice: } \\
\text { Supplier Development/Selection }\end{array}$ & \\
\hline $\begin{array}{l}\text { Definition ( } 25 \text { words or les } \\
\text { Determine if a supplier is capable } \\
\text { commercial suppliers where poss }\end{array}$ & duct to meet design requirements including \\
\hline $\begin{array}{l}\text { PRP Subprocesses: } \\
\text { Design/Product \& Process Defini }\end{array}$ & \\
\hline Business Practice Type: $T$ & \\
\hline $\begin{array}{l}\text { Includes: } \\
\text { Process Characterization } \\
\text { Process Development } \\
\text { Relationship Development } \\
\text { Technology Transfer (Bilateral) } \\
\text { Commercial Parts Selection }\end{array}$ & $\begin{array}{l}\text { Doesn't Include: } \\
\text { Supplier Certification/Qualification } \\
\text { Supplier Management }\end{array}$ \\
\hline
\end{tabular}

\section{Business Practice:}

Identify Nuclear Stockpile Needs \& Issues with DOD Customers

Definition (25 words or less):

Identify needs \& issues with nuclear stockpile; Develop plan to address issues \& concerns; Convince customer of needs \& plan viability; Begin detailed requirement negotiation with customer. Begins with identifying need. Ed with customer requirements.

PRP Subprocesses:

Marketing/Demand Generation

Business Practice Type: Technical Procedure

Includes:

High degree of customer interactions

Strategic Considerations

Scope of Work

Doesn't Include:

Firm Requirements Defn

Significant Concurrent Eng.

Tactical Considerations

Disposition Planning 
Business Practice:

Negotiating Customer/Supplier Requirements

Definition (25 words or less):

The process of understanding what the product to be delivered must do. Begins with Phase 1

authorization letter and ends with requirements document. STS

PRP Subprocesses:

Marketing/Demand Generation, Design/Product \& Process Definition

Business Practice Type: Technical Procedure

\section{Includes: \\ Doesn't Include:}

Documenting and recording the military

characteristics, STS, CRL, traceability of

requirements; ICD's (living documents)

Design definition, i.e., ML's, AY's, PS's, etc.

Business Practice:

Creating Design Definition

Definition (25 words or less):

Creating product files which describes the design. Begins with MC or CRL and ends with CER.

PRP Subprocesses:

Design/Product \& Process Definition

Business Practice Type: Technical Procedure

Includes:

Drawing specifications, i.e., ML's, AY's, PS's,

Doesn't Include:

CK's, CD's, SS's, etc.

MC, STS, ICD, CDR, CRL

\section{Business Practice:}

Conceptual Design

Definition (25 words or less):

Creating a preliminary concept based on requirements. Begins with customer requirements and ends with conceptual design.

PRP Subprocesses:

Design/Product \& Process Definition

Business Practice Type: Technical Procedure

Includes:

Design layouts, margin analysis, CDR's, Concepts

using commercial product in Phase 1 final report

Doesn't Include:

Formal drawing or testing 
Business Practice:

Engineering Feasibility Study

Definition (25 words or less):

Prove initial design ideas meet basic requirements. Begins with conceptual design review and ends with "prototype design review". Phase 2 final report.

PRP Subprocesses:

Design/Product \& Process Definition

Business Practice Type: Technical Procedure

Includes:

System design layouts, modeling, some fab., preproduction discussions, reliability assessments, nuclear safety, prod. process capability, prelim. cost estimates (Phase 2A)

\section{Doesn't Include:}

Production Fabrication, formal engineering release.

\section{Business Practice:}

Engineering Development

Definition (25 words or less):

Creating a documented and tested design with fabricated hardware. Systems Phase 3 authorization.

Begins with Component Request Letter (CRL) and ends with prototype hardware.

PRP Subprocesses:

Design/Product \& Process Definition

Business Practice Type: Technical Procedure

\begin{tabular}{l|l}
\hline Includes: & Doesn't Include:
\end{tabular}

Iterating design, testing, model feedback, special

processes char., tester/gage dev., prod. budgets, ID

long lead items, supplier qualification, production

process selection, MRS.

\section{Business Practice:}

Production Readiness

Definition (25 words or less):

The combined effort of the DA/PA to provide an atmosphere for WR production. Begins with CDR and ends with QER/CER.

\section{PRP Subprocesses:}

Design/Product \& Process Definition, Get Materials, Production PIng \& Sched

Business Practice Type: Technical Procedure

\section{Includes:}

Production readiness review, process prove in, manufacturing documentation, EQ's, DOE money committed.

\section{Doesn't Include:}

WR production. 
Business Practice:

Production

Definition (25 words or less):

Procurement and fabrication of WR product per directed schedules. Begins CER and ends with DOE acceptance.

PRP Subprocesses:

Fabrication \& Assembly

Business Practice Type: Technical Procedure

Includes:

Doesn't Include:

Process control rework, inspection SXR's SIER's, Development hardware

production management, quality assurance, SPC,

D-testing, assembly

Spec test hardware

\section{Business Practice:}

Stockpile Stewardship

Definition (25 words or less):

The responsibility to evaluate, maintain, and/or upgrade the stockpile. Begins IOC and ends with disposition.

PRP Subprocesses:

Field Service, Disposal

Business Practice Type: Technical Procedure

\section{Includes:}

Field retrofits, surveillance, dismantlement,

disposal, LLCE's, military liaison

Doesn't Include:

Feedback to Demand Gen. Phase 2

Feedback to components

\section{Business Practice:}

Identifying and Securing Resources

Definition (25 words or less):

Identify resources; Negotiate priorities/set up teams. Begins with customer commitment. Ends with team authorized.

PRP Subprocesses:

Design/Product \& Process Definition

Business Practice Type: Program Management

Includes:

Acquiring Commitments from resource providers

Doesn't Include:

Product Realization Activities

Disposition Planning 
Business Practice:

Develop Plan/Schedule for Product Delivery

Definition (25 words or less):

Identify milestones/"external" deliverables; Identify WBS; Contingency planning (risk mitigation);

Identify intra project deliverables. Begins with team authorization. Ends with agreement on plan detail.

PRP Subprocesses:

Planning/Scheduling

Business Practice Type: Program Management

Includes:

See definition

\section{Doesn't Include:}

Fully integrated plan across DAVA

Formal risk mgmt

Technology constraints

Disposition planning

Consistent approach to concurrent engineering

\section{Business Practice:}

Assure Acceptable Materials/Components Available As Needed

Definition (25 words or less):

Resolve make/buy issues; Oversee development of alternate vendors as required; Monitor.

PRP Subprocesses:

Getting Materials

Business Practice Type: Program Management

Includes:

DA/PA redundancy of effort

Doesn't Include:

Coordinated DA (Development)/PA (Production)

material/parts acquisition

\section{Business Practice:}

Assure Total Customer Satisfaction.

Definition (25 words or less):

Monitor cost/performance schedule; Mgmt Priorities; Change Mgmt. Begins with demand generation phase 3 FPU. Ends with last delivered product - phase 6 last delivery.

\section{PRP Subprocesses:}

All

Business Practice Type: Program Management

Includes:

Oversight of ALL aspects of project to assure

Doesn't Include:

customer satisfaction

\section{Disposition planning}




\section{Business Practice:}

Open Requirements Scheduling

\section{Definition (25 words or less):}

Provides a master schedule for the needs for all products that are part of a project or program through all levels of assembly. Begins with a customer order and ends with requisitions for purchased products and schedules for build products.

\section{PRP Subprocesses:}

Production Planning \& Scheduling

Business Practice Type: Materials Management

\begin{tabular}{l|l}
\hline Includes: & Doesn't Include:
\end{tabular}

PRT SNL

PP\&S SNL

Open Requirements at $\mathrm{KCP}$

\section{Business Practice:}

Procurement (Acquisition)

Definition (25 words or less):

Process starts with the SOW (Requisition) and ends with receipt of material by user/receiving function.

\section{PRP Subprocesses:}

Get Material

Business Practice Type: Materials Management

Includes:

Cost estimates

Doesn't Include:

RFQ

Contract negotiations

SOW/Product definition

P.O./Contract issues

Assurance of supply (strategy)

Quality Reqmts.

Funding

\section{Business Practice:}

Receiving

\section{Definition (25 words or less):}

Documentation of receipt of material, inspection of quality reqmts. non-conforming material control and priority setting. Begins with receipt of materials and ends with delivering acceptable material to stores.

\section{PRP Subprocesses:}

Get Materials

Business Practice Type: Materials Management

Includes:

Receiving inspection

Non-conforming material disposition

Setting of priorities 


\section{Business Practice:}

Bonded Stores

Definition (25 words or less):

Limited access area for controlling and storing material. Begins with receipt of material from recovery.

Ends with delivery of material to a user.

PRP Subprocesses:

Get Materials, Fabrication \& Assembly

Business Practice Type: Materials Management

Includes:

Inventory control

Special environmental shelf life monitoring

May include automated retrieval

\section{Business Practice:}

Shipping

Definition ( 25 words or less):

The practice of preparing material for shipping to the customer. Begins with receipt of materials required to satisfy customer orders. Ends with shipment and delivery of material to the customer.

\section{PRP Subprocesses:}

Certify and Deliver

Business Practice Type: Materials Management

Includes:

Packing

Document preparation

Labeling

Deliver to carrier

\section{Doesn't Include:}

Work-in-progress status

Business Practice:

Supplier Management (SQP)

Definition (25 words or less):

Process of establishing and monitoring known suppliers for providing required materials.

PRP Subprocesses:

Production Planning \& Scheduling, Get Materials, Production

Business Practice Type: Materials Management

Includes:

Supplier Performance Evaluations

Doesn't Include:

Approved supplier list (B-items) (CASL)

Supplier Development/Selection

Supplier Certification/Qualification 
Business Practice:

Internal Transportation

Definition (25 words or less):

Internal movement of material to using groups.

PRP Subprocesses:

Fabrication \& Assembly

Business Practice Type: Materials Management

\begin{tabular}{l|l} 
Includes: & Doesn't Include:
\end{tabular}

Movement within location (between buildings or

across buildings)

\section{Business Practice:}

Product/ Process Qualification

Definition (25 words or less):

The process of assuring that product and all associated process are capable of meeting customer requirements. Begins with requirement verification. Ends with regmt. validation

PRP Subprocesses:

All

Business Practice Type: Quality

Includes:

EP401401

EP401100

M\&TE Eq

Defining software

Qualification criteria

Customer Regmts

\section{Business Practice:}

Nonconforming Material Disposition

Definition (25 words or less):

The process of disposition and corrective action associated with nonconforming material. Begins with documentation of product not meeting reqmis. Ends with reinstatement of product into production flow.

\section{PRP Subprocesses:}

Get Material, Fabrication \& Assembly

Business Practice Type: Quality

Includes:

SXR

Corrective action

Disposition

ACO
Doesn't Include:

EP401011

Supplier Qualification

\section{Doesn't Include:}

Inspection 
Business Practice:

Process Control

Definition (25 words or less):

The process of assuring manufacturing process stability. Begins with determining criticality of processes.

Ends with a stable process.

PRP Subprocesses:

Fabrication \& Assembly

Business Practice Type: Quality

Includes:

Capability studies

Corrective action

Doesn't Include:

Inspection for product acceptance

Control charts

Calibration

Inspection

Preventive maintenance

Input phase output variable

\section{Business Practice:}

Product Acceptance and Delivery

Definition (25 words or less):

The process of assuring and providing quality evidence that the product has met specified reqmts. Begins with defining product acceptance criteria. Ends with DOE QAIP.

PRP Subprocesses:

Fabrication \& Assembly, Certification \& Delivery

Business Practice Type: Quality

Includes:

Defining product acc criteria

Quality data package

QAIP

Source acceptance (EP401413)

Doesn't Include:

Material acceptance

\section{Business Practice:}

Material Acceptance

Definition (25 words or less):

The process of assuring and providing quality evidence that material/piece parts have met specified reqmits. The process begins with identification of incoming acceptance criteria. Ends with quality acceptance of material/piece parts.

PRP Subprocesses:

Get Materials, Fabrication \& Assembly

Business Practice Type: Quality

\section{Includes:}

Materials, Piece parts, Source Acceptance

(EP401410)

PMQP's/II's

Defining material/piece parts acceptance criteria

\section{Doesn't Include:}

Product Acceptance 


\section{Business Practice:}

Calibration

\section{Definition (25 words or less):}

The process of assuring the accuracy of equipment. Begins with identification of equipment in a recall system and ends with released calibration of equipment back to operations.

PRP Subprocesses: Design/Product \& Process Definition, Get Materials,

Fabrication \& Assembly, Field Service, Disposal

Business Practice Type: Quality

Includes:

EP401560

SLP1053

Doesn't Include: Qualification of Eq

Recall System (notification of users of out of cal.

eq.)

\section{Business Practice:}

Supplier Certification/Qualification

\section{Definition (25 words or less):}

The process of determining that a supplier is capable of providing product within specified limits.

Certification is based on evaluation of the supplier quality mgmt system and technical processes. Begins with identifying a potential supplier. Ends with the results of evaluation.

\section{PRP Subprocesses:}

Design/Product \& Process Definition, Get Materials, Fabrication \& Assembly

\section{Business Practice Type: Quality}

Includes:

MDE Project Mgmt Template

EP401408

EP401418

RP401412

EP401563

Report

\section{Doesn't Include:}

Incoming/Product Acceptance

Expiration

Supplier Development/Selection

Supplier Management

\section{Business Practice:}

Performance Management Process

Definition (25 words or less):

The process attempts to provide expectations for individuals for the coming year, rate the results and provide input to the compensation process.

\section{PRP Subprocesses:}

All

\section{Business Practice Type: People}

Includes:

Expectations

Work Approaches

Assignments
Doesn't Include:

A clear connection to compensation or other rewards or recognition A provision to clearly teamwork 


\section{Business Practice:}

Training for Product Realization Process

Definition (25 words or less):

The process of training begins with identification of a need, the development of instruction material, finding teachers, conducting classes or OJT and measuring the impact.

\section{PRP Subprocesses:}

All

\section{Business Practice Type: People}

Includes:

Currently training includes on site, University

programs, INTEC, short courses etc.

Production Training per QC-1

\section{Doesn't Include:}

Formal OJT system

\section{Business Practice:}

Staffing Projects (Getting Right People, Right Place, Right Time)

Definition (25 words or less):

Begins with project authorization and funding. Ends with a completion and staff movement, reassignment or a new project.

\section{PRP Subprocesses:}

All

\section{Business Practice Type: People}

\section{Includes:}

Matrix support

Postings

Direct transfers

New Hires

Loans of people

Residuals

Doesn't Include:

Consistent Co-location

(systems orgs do better)

Virtual co-location

Electronic fast response

Team building

\section{Business Practice:}

Team Building

\section{Definition (25 words or less):}

Begins with the recognition that a team is needed for the job. Ends when a high performing team is operational.

\section{PRP Subprocesses:}

All

\section{Business Practice Type: People}

\section{Includes:}

Forming, norming, storming, and performing

Continued team building

Doesn't Include:

Staffing

Formal training, today 


\section{Business Practice:}

Team Operation

Definition (25 words or less):

Begins after formation. Ends when the job is done.

PRP Subprocesses:

All

Business Practice Type: People

Includes:

Continuity

Performance

Common vision

Communications

\begin{tabular}{l} 
Doesn't Include: \\
Formation \\
Team building \\
Staffing \\
Training \\
\hline
\end{tabular}

Business Practice:

Strategic Planning

Definition (25 words or less):

Generates longer range organization of mission, vision, values and objectives in response to Leadership, Environmental scans, Current strengths/weaknesses strategic partners and customer expectations.

PRP Subprocesses:

Marketing/Demand Generation

Business Practice Type: Strategic Planning

\begin{tabular}{l|l} 
Includes: & Doesn't Include: \\
\hline
\end{tabular}

Team building as part of process $\quad$ Operational Planning

\begin{tabular}{l|l}
\hline Long term perspective & Program/Project Planning \\
\hline
\end{tabular}

Resource Mgmt

Business Practice:

Manage PRP Communication System

Definition (25 words or less):

The process of managing the PRP communications system begins with establishing and maintaining a reliable enterprise network and ends with deploying and supporting communications tools at the desktop. The as-is PRP communications capabilities are not integrated and managed as a system, but rather as a collection of organizationally and financially independent entities including production agency. Each organization makes decision based on local optimization. The creation of the CIO has started the integration effort, but much work remains.

\section{PRP Subprocesses:}

All

Business Practice Type: Information System

Includes:

Networks (classified, unclassified), security $h / w, s / w$ and plans, collaborative environments, email, office automation, internal \& external connectivity, access to corporate systems, SNLmail

\author{
Doesn't Include: \\ Function specific $s / w$ (electrical and mechanical \\ applications, etc.), \\ telephones, \\ FAX machines
}


Business Practice:

Manage Product Definition and Process Information During Development

\section{Definition (25 words or less):}

The management of product definition and process information begins with conceptual design (requirements) and ends with formal approval and release to the archival system. Manage includes capture, store, retrieve, route. Engineering defines read/write privileges.

\section{PRP Subprocesses:}

Design/Product \& Process Definition

Business Practice Type: Information System

\section{Includes:}

product definition, process information, design tools, visualization \& simulation tools, managing work in progress information, configuration management of data, assembly planning

\section{Doesn't Include:} MRP tools, project management tools, ER system

Business Practice:

Engineering Release and Change Order Process

\section{Definition (25 words or less):}

The Engineering Release and Change Order Process begins with the initiation of the formal release of a drawing, document, etc. and ends with inputting the released information and the associated ER or CO into the current "Configuration Management System" and the "Image Management System." The information is also distributed to whoever needs it, including the DOE complex for production and outside suppliers.

\section{PRP Subprocesses:}

All

Business Practice Type: Information System

\section{Includes:}

release procedures (EP401xxx), configuration management of released information
Doesn't Include: archival procedures, management of the archived information 


\section{Business Practice:}

Manage Archived Information

\section{Definition (25 words or less):}

The management of archived information begins with the release of information to the appropriate archival system and ends in accordance with established records retention schedules.

PRP Subprocesses:

All

Business Practice Type: Information System

Includes:

Doesn't Include:

storage and retrieval,

configuration management of archived information,

current systems include:

IMS, CMS, ROA, PTD, Specifications,

Film bank, etc.

\section{Business Practice:}

Generation and Maintenance of Product and Process Flow Diagrams

Definition (25 words or less):

This process begins with product and process definition generation and ends with release to archival system. It defines and provides a record of the product hierarchical design tree and associated manufacturing process flows.

\section{PRP Subprocesses:}

All

Business Practice Type: Information System

Includes:

Travelers,

Doesn't Include:

BOMs,

OPs,

product top-down BOM,

CMS,

MLs,

PXs 
Business Practice: Traceability of Design Requirements and Intent, Rationale and Decisions, and Processes

Definition (25 words or less):

The current process is a people intensive search through individual, organizational and corporate databases, as well as pick your brain discussions and speculation. A systematic approach including an accessible knowledge base does not exist and is desperately needed.

PRP Subprocesses:

All

Business Practice Type: Information System

\begin{tabular}{l|l} 
Includes: & Doesn't Include:
\end{tabular}

top down and bottom up requirements traceability,

CDRs,

CDs,

STS,

MCs,

CTF

Business Practice: Accessing Official Policies/Procedures From Associated Production And Design

Environments, Internal And External.

Definition (25 words or less):

This process involves enabling electronic access at the desktops to official policies and procedures associated with product realization.

\section{PRP Subprocesses:}

All

Business Practice Type: Information System

Includes:

KCD Command Media,

Sandia EVE and Policy Media,

SAROS

\section{Business Practice:}

Project Management Information Process

Definition (25 words or less):

The project management information process begins with scoping the project followed by the preparation of schedules, budgets, work break down schedules, identification of required resources, etc. This information continues to be updated and tracked through the life of the project.

\section{PRP Subprocesses:}

All

Business Practice Type: Information System

Includes:

Project planning tools (PDI, uS, etc),

budget,

Doesn't Include:

work breakdown schedules,

etc.

\section{Doesn't Include:}

Production planning and scheduling, shop floor planning 


\section{Business Practice:}

Production Planning And Scheduling And Shop Floor Planning

Definition (25 words or less):

This process begins with migrating the product definition into manufacturing and ends with detailed scheduling of manufacturing systems and processes.

PRP Subprocesses: Planning and Scheduling, Get Materials, Fabrication \& Assembly, Certification and Delivery

Business Practice Type: Information System

Includes:

MRP,

shop floor planning and control,

build schedules,

customer requirements, etc.

\section{Business Practice:}

Preparation and Maintenance of Dismantlement Database

\section{Definition (25 words or less):}

This process begins with accessing, extracting, and compiling information from databases on product definition, process and materials specifications, product and process flow charts and information models and ends with database maintenance of dismantlement information.

\section{PRP Subprocesses:}

Disposal

Business Practice Type: Information System

\section{Includes:}

product definition by suffix with associated

material and process information

\section{Doesn't Include:}

Product design and process development projects

\section{Doesn't Include:}

process material consumed that could have an effect but not specified in product definition process material consumed that could have an effect but not specified in product definition

\section{Business Practice:}

Collecting and Assembling QC Data

\section{Definition (25 words or less):}

This process begins with collecting $\mathrm{QC}$ data and ends with assembling the data in a managed database. This database provides the information used to support the preparation of the certificate of compliance.

\section{PRP Subprocesses:}

Certify and Deliver

Business Practice Type: Information System

Includes:

all information collected during fabrication and certification process required by product acceptance specifications and process engineering

requirements, tester data, PTD system, ROAs,

VADA,

legacy PTD systems, etc.

\section{Doesn't Include:}


Attachment 5: Pugh Scores for Business Practices as Individual Processes and for Impact on Entire PRP Process

\begin{tabular}{|c|c|c|c|c|c|c|c|c|c|c|c|c|c|c|}
\hline \multirow{3}{*}{ Business Practice } & \multicolumn{14}{|c|}{ Individual } \\
\hline & \multicolumn{2}{|c|}{ CT } & \multicolumn{2}{|c|}{ Flex } & \multicolumn{2}{|c|}{ Cost } & \multicolumn{2}{|c|}{ PQ } & \multicolumn{2}{|c|}{ Best } & \multirow{2}{*}{$\frac{\text { WT }}{+}$} & \multirow{2}{*}{ WT } & \multirow{2}{*}{$\frac{\text { Tot }}{+}$} & \multirow{2}{*}{ Tot } \\
\hline & + & - & + & - & + & - & + & - & + & - & & & & \\
\hline Internal Transportation & & 1 & & & & & & & & & 0 & -5 & 0 & -1 \\
\hline PRP Communication System & & 1 & & & & 1 & & 1 & & & 0 & -10 & 0 & -3 \\
\hline Manage Product Defn Info & & 2 & & 1 & & 1 & & 1 & & 1 & 0 & -22 & 0 & -6 \\
\hline ER \& CO Process & & 2 & 1 & & & 1 & 1 & & & & 7 & -13 & 2 & -3 \\
\hline Manage Archived Information & 1 & & & & 1 & & & & & 1 & 8 & -2 & 2 & -1 \\
\hline Generate \& Maint Prod Info & 2 & & & & 2 & & 1 & & 2 & & 22 & $\underline{0}$ & 7 & 0 \\
\hline Performance Mgmt Process & & 1 & & 2 & & & & & & 2 & 0 & -19 & $\underline{0}$ & -5 \\
\hline Trng for PRP & & 1 & & 1 & & & 1 & & & 1 & 2 & -12 & 1 & -3 \\
\hline Staffing for Project & & 2 & & 2 & & 2 & 1 & & & 1 & 2 & -28 & 1 & -7 \\
\hline Team Building & & 1 & 1 & & & 2 & 1 & & 1 & & 9 & -11 & 3 & -3 \\
\hline Team Operations & & 2 & 1 & & & 1 & 1 & & 1 & & 9 & -13 & 3 & -3 \\
\hline Strategic Planning & & 2 & & & & 1 & & & & 1 & 0 & -15 & $\underline{0}$ & -4 \\
\hline Acquire Funding & & 1 & 1 & & & & & & 1 & & 7 & -5 & 2 & -1 \\
\hline Planning to Spend & & 1 & 1 & & & & & & & 1 & 5 & -7 & 1 & -2 \\
\hline Cost Collection & & & & 2 & & 1 & & & & 2 & 0 & -17 & 0 & -5 \\
\hline Case Closing & & & & 1 & & & & & & 1 & 0 & -7 & 0 & -2 \\
\hline Id Nuclear Stockpile Needs & & & 2 & & & 1 & & 1 & & 2 & 10 & -9 & 2 & -4 \\
\hline Id \& Secure Resources & & 2 & & 2 & & 2 & & & & 1 & 0 & -28 & 0 & -7 \\
\hline Traceability of Design Rqmts & & 2 & & 2 & & 2 & & 2 & & 2 & 0 & -34 & 0 & -10 \\
\hline Access to Official Policies/Proc & 1 & & 1 & & 1 & & 1 & & 1 & & 17 & 0 & 5 & 0 \\
\hline Project Management Info & & 1 & & 1 & & 2 & & 1 & & 2 & 0 & -22 & 0 & -7 \\
\hline PP\&S SFC & & 1 & & 1 & & 1 & & & & 1 & $\underline{0}$ & -15 & 0 & -4 \\
\hline Maint of Dismantlement & & 1 & & & & 2 & 1 & & & & 2 & -11 & 1 & -3 \\
\hline QC Database & & 1 & & 1 & & 2 & & & & 2 & $\underline{0}$ & -20 & 0 & -6 \\
\hline Supplier Certification & & 2 & & 1 & & 2 & & & & 2 & 0 & -25 & 0 & -7 \\
\hline Calibration & & 1 & & 1 & & 1 & & & & & 0 & -13 & $\underline{0}$ & -3 \\
\hline Material Acceptance & & 2 & & 1 & & 2 & 1 & & & 2 & 2 & -25 & 1 & -7 \\
\hline Product Acceptance & & 1 & & 1 & & 1 & 1 & & & 2 & 2 & -17 & 1 & -5 \\
\hline Process Control & & 1 & 1 & & & 1 & 2 & & 1 & & 11 & -8 & 4 & -2 \\
\hline Non-Conf Matl Disposition & & 1 & & 2 & & 1 & 2 & & & & 4 & -18 & 2 & -4 \\
\hline Develop Plan/Sched & & 1 & & 1 & & 1 & & & & 2 & 0 & -17 & 0 & -5 \\
\hline Assure Acc Matls & & 2 & & 2 & & 2 & & 2 & & 2 & 0 & -34 & 0 & -10 \\
\hline Assure Total Customer Sat & 1 & & 1 & & & 1 & 1 & & & 1 & 12 & -5 & 3 & -2 \\
\hline Negotiate Cust/Sup Rqmts & & $\underline{2}$ & & 1 & & & & 1 & & & 0 & -17 & 0 & -4 \\
\hline Create Design Defn & & 2 & 2 & & & 2 & & 1 & & 1 & 10 & -20 & 2 & -6 \\
\hline Conceptual Design & & 2 & 1 & & & & & 2 & & 1 & 5 & -16 & 1 & -5 \\
\hline
\end{tabular}




\begin{tabular}{|c|c|c|c|c|c|c|c|c|c|c|c|c|c|c|}
\hline \multirow{3}{*}{ Business Practice } & \multicolumn{14}{|c|}{ Individual (Continued) } \\
\hline & \multicolumn{2}{|c|}{$\mathbf{C T}$} & \multicolumn{2}{|c|}{ Flex } & \multicolumn{2}{|c|}{ Cost } & \multicolumn{2}{|c|}{ PQ } & \multicolumn{2}{|c|}{ Best } & \multirow{2}{*}{$\frac{\text { WT }}{+}$} & \multirow{2}{*}{ WT } & \multirow{2}{*}{$\frac{\text { Tot }}{+}$} & \multirow{2}{*}{ Tot } \\
\hline & + & - & + & - & + & - & + & - & + & - & & & & \\
\hline Engineering Feasibility Study & & 1 & & & & & & 1 & & 1 & 0 & -9 & $\underline{0}$ & -3 \\
\hline Engineering Development & & 2 & & 2 & & 2 & & 2 & & 2 & 0 & -34 & 0 & -10 \\
\hline Production Readiness & & 2 & & & & 1 & 1 & & & 2 & 2 & -17 & 1 & -5 \\
\hline Production & & 1 & & 1 & & 1 & & 1 & & 1 & 0 & -17 & $\mathbf{0}$ & -5 \\
\hline Stockpile Stewardship & & 2 & & & & 1 & & 1 & & 2 & $\underline{0}$ & -19 & $\underline{0}$ & -6 \\
\hline Open Ramts Sched & & 1 & 1 & & & & & & & 1 & 5 & .7 & 1 & -2 \\
\hline Procurement & & 1 & & 1 & & & & & & 1 & 0 & -12 & $\underline{0}$ & -3 \\
\hline Receiving & & 2 & & 1 & & & & & & 1 & 0 & -17 & 0 & -4 \\
\hline Bonded Stores & & 1 & & & 1 & & & & & & 3 & -5 & 1 & -1 \\
\hline Shipping & & 1 & & & 1 & & & & & & 3 & -5 & 1 & -1 \\
\hline Supplier Selection & & 2 & 1 & & & 2 & & & & 1 & 5 & -18 & 1 & -5 \\
\hline Supplier Mgmt & & 1 & & 1 & & & & 1 & & 1 & 0 & -14 & 0 & -4 \\
\hline Product/Process Qualification & & 1 & 2 & & & 1 & 2 & & & & 14 & -8 & 4 & -2 \\
\hline
\end{tabular}

\begin{tabular}{|c|c|c|c|c|c|c|c|c|c|c|c|c|c|c|}
\hline \multirow{3}{*}{ Business Practice } & \multicolumn{14}{|c|}{ System } \\
\hline & \multicolumn{2}{|c|}{$\mathbf{C T}$} & \multicolumn{2}{|c|}{ Flex } & \multicolumn{2}{|c|}{ Cost } & \multicolumn{2}{|c|}{ PO } & \multicolumn{2}{|c|}{ Best } & \multirow{2}{*}{$\begin{array}{c}\text { WT } \\
+\end{array}$} & \multirow{2}{*}{$\frac{\mathbf{W T}}{-}$} & \multirow{2}{*}{ Tot } & \multirow{2}{*}{ Tot } \\
\hline & + & - & + & - & + & - & + & - & + & - & & & & \\
\hline Internal Transportation & & 1 & & & & & & & & & 0 & -5 & 0 & -1 \\
\hline PRP Communication System & & 1 & & & & 1 & & & & 1 & 0 & -10 & 0 & -3 \\
\hline Manage Product Defn Info & & 1 & & 1 & & 1 & & 1 & & 1 & 0 & -17 & 0 & -5 \\
\hline ER \& CO Process & & 2 & & 1 & & 1 & 1 & & & 1 & 2 & -20 & 1 & -5 \\
\hline Manage Archived Information & & & & & & & & & & & 0 & 0 & 0 & 0 \\
\hline Generate \& Maint Prod Info & & 1 & & & & 1 & & & & 2 & 0 & -12 & 0 & -4 \\
\hline Performance Mgmt Process & & 1 & & & & & & & & 2 & 0 & -9 & 0 & -3 \\
\hline Trng for PRP & & 1 & & & & 1 & & 1 & & 1 & 0 & -12 & 0 & -4 \\
\hline Staffing for Project & & 2 & & 2 & & 2 & & & & 2 & 0 & -30 & 0 & -8 \\
\hline Team Building & & 1 & & & & & & & & 1 & 0 & -7 & 0 & -2 \\
\hline Team Operations & & 1 & & & & & & & & & 0 & -5 & 0 & -1 \\
\hline Strategic Planning & & 1 & & & & & & & & 1 & 0 & -7 & 0 & -2 \\
\hline Acquire Funding & & 1 & & 1 & & & & & & 1 & 0 & -12 & 0 & -3 \\
\hline Planning to Spend & & 1 & & & & 1 & & & & 1 & 0 & -10 & 0 & -3 \\
\hline Cost Collection & & & & 2 & & 1 & & & & 2 & 0 & -17 & 0 & -5 \\
\hline Case Closing & & & & 1 & & & & & & 1 & 0 & -7 & 0 & -2 \\
\hline Id Nuclear Stockpile Needs & & & & & & & & & & & 0 & 0 & 0 & 0 \\
\hline Id \& Secure Resources & & 2 & & 1 & & 1 & & & & 1 & $\mathbf{0}$ & -20 & 0 & -5 \\
\hline Traceability of Design Rqmts & & 2 & & 1 & & 1 & & 2 & & 2 & 0 & -26 & 0 & -8 \\
\hline
\end{tabular}




\begin{tabular}{|c|c|c|c|c|c|c|c|c|c|c|c|c|c|c|}
\hline \multirow{3}{*}{ Business Practice } & \multicolumn{14}{|c|}{ System (Continued) } \\
\hline & \multicolumn{2}{|c|}{ CT } & \multicolumn{2}{|c|}{ Flex } & \multicolumn{2}{|c|}{ Cost } & \multicolumn{2}{|c|}{ PQ } & \multicolumn{2}{|c|}{ Best } & \multirow{2}{*}{$\begin{array}{l}\text { WT } \\
+ \\
\end{array}$} & \multirow{2}{*}{$\begin{array}{l}\mathbf{W T} \\
-\end{array}$} & \multirow{2}{*}{$\begin{array}{l}\text { Tot } \\
+\end{array}$} & \multirow{2}{*}{ Tot } \\
\hline & + & - & + & $=$ & + & - & + & - & + & - & & & & \\
\hline Access to Official Policies/Proc & 1 & & & & & & & & & & 5 & 0 & 1 & 0 \\
\hline Project Management Info & & 1 & & & & 1 & & & & 1 & 0 & -10 & 0 & -3 \\
\hline PP\&S SFC & & & & & & 1 & & & & & 0 & -3 & 0 & -1 \\
\hline Maint of Dismantlement & & & & & & & & & & & 0 & $\mathbf{0}$ & 0 & 0 \\
\hline QC Database & & 1 & & 1 & & 1 & & & & & $\underline{0}$ & -13 & 0 & -3 \\
\hline Supplier Certification & & 2 & & 1 & & 1 & & & & 2 & 0 & -22 & 0 & -6 \\
\hline Calibration & & & & & & 1 & & & & & 0 & -3 & 0 & -1 \\
\hline Material Acceptance & & 2 & & 1 & & 2 & & & & 2 & 0 & -25 & 0 & -7 \\
\hline Product Acceptance & & 1 & & 1 & & 1 & & & & 1 & 0 & -15 & 0 & -4 \\
\hline Process Control & & 1 & & & & & & & & 1 & 0 & -7 & $\underline{0}$ & -2 \\
\hline Non-Conf Matl Disposition & & 1 & & 1 & & 1 & & & & 1 & 0 & -15 & 0 & -4 \\
\hline Develop Plan/Sched & & 1 & & & & & & & & & 0 & -5 & 0 & -1 \\
\hline Assure Acc Matls & & 2 & & 1 & & 1 & & 1 & & 2 & $\mathbf{0}$ & -24 & $\underline{0}$ & -7 \\
\hline Assure Total Customer Sat & & & & & & 1 & 1 & & & 1 & 2 & -5 & 1 & -2 \\
\hline Negotiate Cust/Sup Rqmts & & 1 & & 1 & & 1 & & & & 1 & 0 & -15 & 0 & -4 \\
\hline Create Design Defn & & 1 & & & & 1 & & 1 & & 1 & 0 & -12 & 0 & -4 \\
\hline Conceptual Design & & 1 & & & & 1 & & 1 & & 1 & $\underline{0}$ & -12 & 0 & -4 \\
\hline Engineering Feasibility Study & & 1 & & & & & & & & & $\underline{0}$ & -5 & $\underline{0}$ & -1 \\
\hline Engineering Development & & 2 & & 1 & & 2 & & 1 & & 1 & 0 & -25 & 0 & -7 \\
\hline Production Readiness & & 1 & & 1 & & 1 & & & & 1 & $\underline{0}$ & -15 & 0 & -4 \\
\hline Production & & 1 & & 1 & & 1 & & & & 1 & $\underline{0}$ & -15 & 0 & -4 \\
\hline Stockpile Stewardship & & & & & & 1 & & 1 & & & 0 & -5 & 0 & -2 \\
\hline Open Rqmis Sched & & & & & & & & & & & 0 & 0 & 0 & 0 \\
\hline Procurement & & 2 & & 2 & & 1 & & & & 2 & $\mathbf{0}$ & -27 & 0 & -7 \\
\hline Receiving & & 1 & & 1 & & & & & & & 0 & -10 & 0 & -2 \\
\hline Bonded Stores & & & & & & & & & & & 0 & 0 & $\underline{0}$ & 0 \\
\hline Shipping & & & & & & & & & & & 0 & 0 & $\underline{0}$ & 0 \\
\hline Supplier Selection & & 2 & & & & 1 & & & & 1 & $\mathbf{0}$ & -15 & $\mathbf{0}$ & -4 \\
\hline Supplier Mgmt & & 1 & & 1 & & 1 & & & & & 0 & -13 & $\underline{0}$ & -3 \\
\hline Product/Process Qualification & & 1 & & & & 1 & & & & & 0 & -8 & $\underline{0}$ & -2 \\
\hline
\end{tabular}


Attachment 6: Histogram of Negative Weighted Totals for

\section{DP Business Practices}

\begin{tabular}{|c|c|}
\hline Business Practice & Neg Total \\
\hline Staffing for Project & 30 \\
\hline Procurement & 27 \\
\hline Traceability of Design Rqunts & 26 \\
\hline Material Acceptance & 25 \\
\hline Engineering Development & 25 \\
\hline Assure Acc Matls & 24 \\
\hline Supplier Certification & 22 \\
\hline ER \& CO Process & 20 \\
\hline Id \& Secure Resources & 20 \\
\hline Manage Product Defn Info & 17 \\
\hline Cost Collection & 17 \\
\hline Product Acceptance & 15 \\
\hline Non-ConfMatl Disposition & 15 \\
\hline Negotiate Cust/Sup Rqmts & 15 \\
\hline Production Readiness & 15 \\
\hline Production & 15 \\
\hline Supplier Selection & 15 \\
\hline OCDatabase & 13 \\
\hline Supplier Mgmt & 13 \\
\hline Generate \& Maint Prod Info & 12 \\
\hline Trng for PRP & 12 \\
\hline Acquire Funding & 12 \\
\hline Create Design Defn & 12 \\
\hline Conceptual Design & 12 \\
\hline PRP Communication System & 10 \\
\hline Planning to Spend & 10 \\
\hline Project Management Unfo & 10 \\
\hline Receiving & 10 \\
\hline Performance Momt Process & 9 \\
\hline Product/Process Qualification & 8 \\
\hline Team Building & 7 \\
\hline Strategic Planning & 7 \\
\hline Case Closing & 7 \\
\hline Process Control & 7 \\
\hline Internal Transportation & 5 \\
\hline Team Operations & 5 \\
\hline Develop Plan/Sched & 5 \\
\hline Assure Total Customer Sat & 5 \\
\hline Engineering Feasibility Study & 5 \\
\hline Stockpile Stewardship & 5 \\
\hline PP\&S SEC & 3 \\
\hline Calibration & 3 \\
\hline
\end{tabular}

\begin{tabular}{|l|c|}
\hline Manage Archived Information & 0 \\
\hline Id Nuclear Stockpile Needs & 0 \\
\hline Access to Official Policies/Proc & 0 \\
\hline Maint of Dismantlement & 0 \\
\hline Open Ramts Sched & 0 \\
\hline Bonded Stores & 0 \\
\hline Shipping & 0 \\
\hline
\end{tabular}

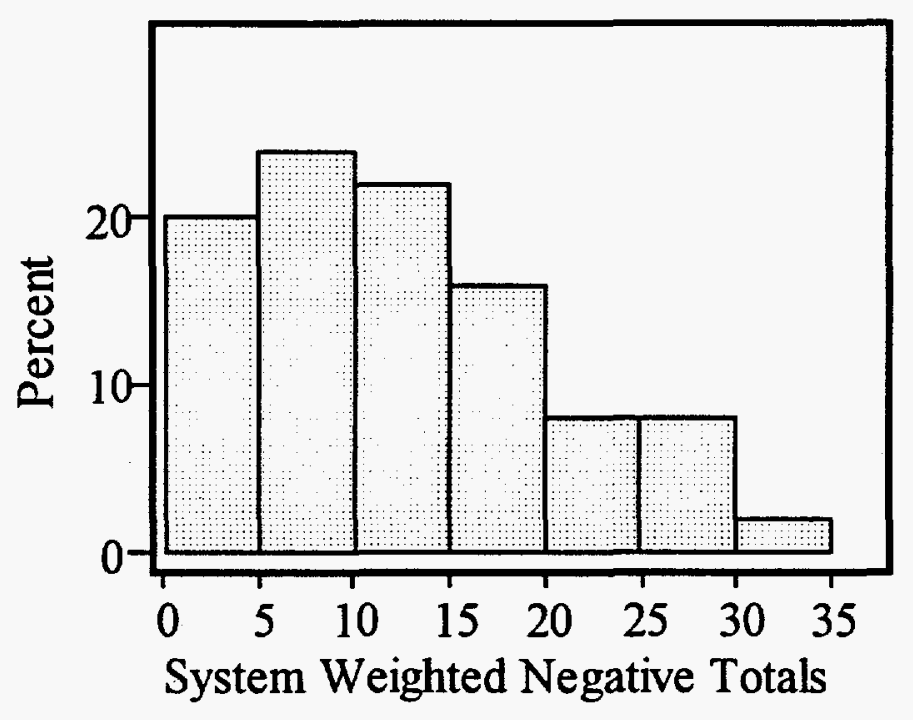


Distribution:

Sandia National Laboratories:

0103 Ron Detry

0202 Gerry Record

0319 Bob Rieden

0427 Bob Bradley

0427 Ray Reynolds

0429 Ron. Andreas

0435 Keith Ortiz

0445 Mike Orrell

0453 Don McCoy

0475 Ron Hartwig

0486 Mark Retter

0507 Brian Behling

0519 Kent Parsons

0521 Gary Laughlin

0533 Warren Sceiford

0614 Nancy Clark

0623 Bob Yuhas

0631 Bill Nickell

0637 Jay Templin

0660 Margaret Olson

0829 Laura Halbleib (10)

0841 Paul Hommert

0863 Carol Murray (10)

0863 Gary Ferguson

0865 Jon Barnette

0872 William E. Packer

0957 Jake F Gonzales

0957 Elena Holland

0957 Karen Long

0985 M. Helen Finley

0985 John Stichman

1158 Alec Willis

1393 Chuck Oien

1435 Harry Saxton

9005 Jim Wright

9036 Doug Henson

9106 Jim Van De Vreugde

9405 Duane Lindner

FM\&T/KC:

281/E2E7 Tom Davis

EOO/2B41 John Lankford

EOO/MZ41 Dominick Palamara 


\section{Copy to:}

1 MS9018 Central Technical Files, 8523-2

5 MS0899 Technical Library, 4414

1 MS0619 Print Media, 12615

2 MS0100 Document Processing, 7613-2

For DOE/OSTI 